\title{
Impaired color word processing at an unattended location: Evidence from a Stroop task combined with inhibition of return
}

\author{
Jong Moon Choi and Yang Seok Cho \\ Korea University, Seoul, Korea \\ AND \\ Robert W. Proctor \\ Purdue University, West Lafayette, Indiana
}

\begin{abstract}
A Stroop task with separate color bar and color word stimuli was combined with an inhibition-of-return procedure to examine whether visual attention modulates color word processing. In Experiment 1, the color bar was presented at the cued location and the color word at the uncued location, or vice versa, with a 100- or 1,050-msec stimulus onset asynchrony (SOA) between cue and Stroop stimuli. In Experiment 2, on Stroop trials, the color bar was presented at a central fixated location and the color word at a cued or uncued location above or below the color bar. In both experiments, with a 100-msec SOA, the Stroop effect was numerically larger when the color word was displayed at the cued location than when it was displayed at the uncued location, but with the 1,050-msec SOA, this relation between Stroop effect magnitude and location was reversed. These results provide evidence that processing of the color word in the Stroop task is modulated by the location to which visual attention is directed.
\end{abstract}

People experience some types of information infrequently but other types frequently. With frequent experience, the cognitive system acquires procedures for processing the information efficiently, so much so that very familiar stimuli, such as words, are often considered to be processed automatically. However, this kind of explanation runs a risk of circular reasoning: A fast response is interpreted as automatic, but automatic processing yields fast responses. To avoid circularity, automatic processing is often said to have at least three features that differentiate it from controlled processing: absence of intention, absence of conscious awareness, and absence of attentional resource demands (Posner \& Snyder, 1975; Saling \& Phillips, 2007; Schneider \& Shiffrin, 1977). The first feature is that the stimulus is processed whenever it appears, regardless of whether there is an intention to process it or not. The second is that automatic processing cannot be discontinued once it starts, because the stimulus is processed without conscious awareness. The third feature is that automatic processing is effortless, requiring little or no attentional capacity. Although the classical view of automaticity was that all of these features are present if processing is automatic, more recent research has suggested that the features are distinct (Moors \& De Houwer, 2006) and do not all have to be evident for a process to be regarded as automatic (e.g., Brown, Gore, \& Carr, 2002; MacLeod \& Dunbar, 1988).
To investigate automatic processing, many tasks have been introduced in which the stimulus contains both taskrelevant and task-irrelevant properties. Such tasks include the flanker task (Eriksen \& Eriksen, 1974), the Simon task (Simon, 1969), the Stroop task (Stroop, 1935), and their variants. For these tasks, poorer performance when the relevant information and irrelevant information are incongruent, as compared with when they are congruent, is often taken as evidence for automatic processing of the irrelevant property. For example, in the classic Stroop color-naming task, a colored color word is presented, and participants are to name the color in which the word is printed. Even though the meaning of the color word is not relevant to the task, response time (RT) is delayed when the printed color and the meaning of the color word are incongruent (e.g., RED in blue), relative to when they are congruent (e.g., RED in red). This RT difference is called the Stroop effect (see MacLeod, 1991, for a review).

The Stroop effect is often considered to demonstrate automatic processing of the color word (see MacLeod, 1991; Moors \& De Houwer, 2006). This automatic view of the Stroop effect is based on the following results: (1) The color word influences the processing of the target color even though participants are told to ignore the color word, and (2) performance is not influenced by the ink color when participants are instructed to read the color word (e.g., Glaser \& Glaser, 1982). These findings can be taken 
to suggest that the automatic process of naming the color word competes with the controlled process of naming the physical color; since the physical color is not named automatically, it does not compete with naming the color word (Lindsay \& Jacoby, 1994).

\section{Does Color Word Processing Require Visual Attention?}

Even though many accounts have been proposed to explain the Stroop effect on the basis of the assumption that the color word is processed automatically (e.g., Cohen, Dunbar, \& McClelland, 1990; MacLeod \& Dunbar, 1988), there are several lines of evidence against automatic processing of the word meaning in the Stroop task. For example, Besner, Stolz, and Boutilier (1997) reported that the color word in the Stroop task did not affect performance unless the participant adopted a mental set of attending to the whole word. In their experiments, in which a version of the task was used in which stimulus colors were indicated by keypresses, the Stroop effect was reduced when a single letter of the color word was colored, as compared with when all the letters were colored. Besner and Stolz (1999) obtained similar results when a single letter with a color different from that of the remaining letters in the color word was cued as the target on all trials. These findings suggest that the meaning of the color word is processed less when attention is directed locally to a letter within the word, rather than more globally to the whole word.

Kahneman and Chajczyk (1983) provided additional evidence that the color word is not processed without visual attention in the Stroop task. They used a version of the Stroop task in which the physical color was conveyed by a color bar and the color word was displayed separately in a neutral grayscale color. In their Experiment 1, the Stroop effect was 50\% smaller when a neutral word was presented along with the color bar and color word than when one was not. This reduction of the Stroop effect by an additional neutral word is called the Stroop dilution effect (Yee \& Hunt, 1991). Kahneman and Chajczyk suggested that the Stroop effect was diluted because the neutral word captured visual attention on approximately half of the trials, with the result that the meaning of the color word was not processed on that half of the trials.

However, the Stroop dilution effect does not necessarily indicate that color word processing requires visual attention. Brown, Roos-Gilbert, and Carr (1995) suggested that Stroop dilution is due to the neutral word's impairing early perceptual processing of the color word. According to Brown et al. (1995), two or more words can be recognized automatically, in parallel, if the words do not impair each other's visual perception. But when multiple words are presented at once, combined representations of the words' features degrade early visual processing of the color word, resulting in impaired recognition. In Brown et al.'s (1995) Experiment 3, the visual complexity was manipulated with various stimuli for diluting the Stroop effect, and the magnitude of the Stroop dilution was found to increase as the visual complexity of the stimuli increased.

In another study, Brown et al. (2002) tested the automaticity of color word processing using an abrupt-onset cue, which was supposed to attract visual attention to its location. In their Experiment 3, the color bar and color word were presented for only $100 \mathrm{msec}$, with the intent of preventing visual attention from shifting to the uncued location. Results showed a Stroop effect of $68 \mathrm{msec}$ when the color word appeared at the cued location (and the color bar at the uncued location), which was larger than the Stroop effect of $47 \mathrm{msec}$ when the color word appeared at the uncued location (and the color bar at the cued location). Although the Stroop effect was reduced when the color word was at the uncued location, the effect was still clearly evident. According to Brown et al. (2002), if word recognition takes place only when focused visual attention is deployed to the color word, no Stroop effect should have been obtained when the word was presented at the uncued location. They reckoned that word recognition takes place without focused visual attention, even though word recognition is modulated by attention.

On the basis of Brown et al.'s (1995) findings, Neely and Kahan (2001) concluded, "The effect that the load-dilution variable has on Stroop interference . . . cannot be taken as strong evidence against SA [semantic activation] automaticity because this variable seems to be affecting SA indirectly through visual feature integration rather than affecting SA directly" (p. 76). However, subsequent research on Stroop dilution has generally not been supportive of the early perceptual interference account. Cho, Lien, and Proctor (2006) conducted a series of experiments showing that the size of the Stroop effect was modulated by the probability that visual attention would be oriented to the color word. In line with Kahneman and Chajzyk's (1983) attentional capture account, Cho et al. assumed that a word is recognized only when it captures attention. Unlike Kahneman and Chajzyk, they also assumed that the color carrier is most likely to capture visual attention initially because the salient color feature has been defined as relevant for the task. According to this view, a separate color word produces a Stroop effect only when attention shifts from the color carrier to the color word. Cho et al. found that the Stroop effect was not modulated by the presence of a neutral word when the color carrier was a color word and, thus, the word was at the location to which attention was initially directed. But the Stroop effect was smaller when the color carrier was a neutral word than when it was a color bar, regardless of whether the carrier's location was fixed or varied (see also Roberts \& Besner, 2005).

According to Cho et al. (2006), when the color carrier was the color word, the color word always received visual attention initially, resulting in the word's being processed on all trials. Consequently, the Stroop effect was not modulated by whether a neutral word was present or not. In contrast, the color word was less likely to receive visual attention when the carrier was the neutral word, because the neutral word received visual attention initially. When the duration of the stimulus display was varied between 100 and $250 \mathrm{msec}$ in Cho et al.'s Experiment 5A, the size of the Stroop effect increased as display duration increased when the color carrier was a neutral word or a color bar, consistent with the view that attention was more likely to shift to the color word the longer it remained visible. Kim, 
Cho, Yamaguchi, and Proctor (2008) showed further that this influence of display duration on the Stroop effect was not due to a decrement in readability. Kim et al. concluded that the Stroop effect in the Stroop dilution paradigm is modulated by the probability that visual attention will be deployed to the color word.

As was noted, Brown et al. (2002) tried to control more directly the location to which attention was oriented by presenting an exogenous cue $100 \mathrm{msec}$ before onset of the Stroop stimuli. In their Experiment 3, the duration of the Stroop display was only $100 \mathrm{msec}$, with the aim of preventing a shift of attention to the uncued location. However, a short display duration alone does not ensure that attention will be focused only at the cued location. (e.g., Lachter, Ruthruff, Lien, \& McCann, 2008). A backward mask, which Brown et al. (2002) did not use, is necessary to ensure that sensory memory of the display does not allow the display's effective duration to be longer than the physical duration. Moreover, placeholders marking the possible stimulus locations, which Brown et al. (2002) also did not use, help prevent the focus of visual attention from drifting over the display. A more important limitation of Brown et al.'s (2002) method, though, is that only a $100-\mathrm{msec}$ interval between cue and display onsets was used. Thus, the location to which attention was presumably directed at onset of the Stroop display was always that at which the cue appeared. A stronger test of the role of attention can be provided by also using a longer interval between onsets of the cue and Stroop stimuli, because attention is known to shift away from the cued location at longer delays. We will discuss this phenomenon, called inhibition of return (IOR), before returning to the issue of attention in the processing of color words in Stroop displays.

\section{Inhibition of Return}

In a target detection task, the response is often facilitated when the target is presented at the location where an exogenous cue was presented previously, relative to when the target is presented at an uncued location. When the interval between cue and target onsets is sufficiently long, however, performance is impaired when the target is presented at the cued location. This phenomenon is called IOR (Lupiáñez, Klein, \& Bartolomeo, 2006; Posner, Rafal, Choate, \& Vaughan, 1985). IOR is considered to occur in order to increase the efficiency of visual search by looking at or attending to novel locations that have not been searched yet. Detection of a stimulus at the cued location might be impaired because the participant's gaze is less likely to be directed to the cued location (oculomotor bias), visual attention is less likely to be oriented to the cued location (attentional bias), or both (Klein \& Taylor, 1994; Prime \& Ward, 2004; Rafal \& Henik, 1994; ReuterLorenz, Jha, \& Rosenquist, 1996; Taylor \& Klein, 2000). These two kinds of bias in IOR are dissociable by the type of responses: Oculomotor bias occurs when eye movement responses are made, whereas attentional bias occurs when manual responses are made and eye movements are restrained (Hunt \& Kingstone, 2003).

Although IOR has usually been found in target detection tasks, several studies have shown that this phe- nomenon can occur in discrimination tasks as well. For example, Lupiáñez, Milán, Tornay, Madrid, and Tudela (1997) found that IOR effects occurred in a color discrimination task at stimulus onset asynchronies (SOAs) between the exogenous cue and the target that are longer than the SOAs at which the IOR effect occurs in target detection tasks. In their Experiment 2B, a target stimulus was presented in one of two boxes flanking a fixation point 100 or $700 \mathrm{msec}$ after an exogenous cue at one of the boxes, and participants were instructed to respond to the color of the target stimulus. RT was $38 \mathrm{msec}$ shorter when the target was presented at the cued location than when it was presented at the uncued location at the $100-\mathrm{msec}$ SOA, whereas it was $30 \mathrm{msec}$ longer when the target was presented at the cued location than when it was presented at the uncued location at the $700-\mathrm{msec}$ SOA. That is, the IOR effect appeared $700 \mathrm{msec}$ after onset of the exogenous cue in the color discrimination task, as compared with $400 \mathrm{msec}$ after cue onset in the detection task.

\section{The Present Study}

We conducted two experiments to examine the role of visual attention in color word processing for the Stroop task. To control the focus of visual attention precisely, a version of the Stroop task with separate color bar and color word stimuli was combined with the IOR procedure. Although an IOR procedure has been used previously to study the version of the Stroop task for which the physical color is integrated with the color word (Vivas \& Fuentes, 2001; see the General Discussion section), it has not been used for the version with separate color and word stimuli, which allows attention to be directed to either the color carrier or the color word. ${ }^{1}$ In Experiment 1, placeholders located above and below fixation designated the stimulus locations. A brief luminance increase of one placeholder served as an exogenous cue, and it was followed after an SOA of 100 or $1,050 \mathrm{msec}$ by onset of the target display, consisting of a color bar and a color word. The color bar was displayed at the upper placeholder and the color word at the lower placeholder, or vice versa. If visual attention is necessary for word processing, no Stroop effect should occur when the color word appears at the unattended location, which would be the uncued location for the 100 -msec SOA and the cued location for the 1,050-msec SOA. In contrast, the Stroop effect should be evident when the color word appears at the attended location, which would be the cued location for the $100-\mathrm{msec}$ SOA and the uncued location for the 1,050-msec SOA.

With the method used in Experiment 1, if the color word appeared at the cued location, the color bar appeared at the uncued location, and vice versa. In Experiment 2, this association between color bar and color word locations on the Stroop trials was eliminated by presenting the color bar at fixation, flanked by a color word at the cued or uncued placeholder above or below the bar. As in Experiment 1, if visual attention is required to process the color word meaning, the word's meaning should not be processed when it is presented at the unattended location. Thus, at the 100-msec SOA, a Stroop effect should be obtained when the color word is presented at the cued loca- 
tion but not when it is presented at the uncued location, whereas at the 1,050-msec SOA, a Stroop effect should be obtained when the color word is presented at the uncued location but not when it is presented at the cued location.

\section{EXPERIMENT 1}

The Stroop effect was examined in the IOR procedure to find out whether the color word in a Stroop display is recognized when it appears at an unattended location. The target color and the color word were displayed separately, one at a placeholder above fixation and the other at a placeholder below fixation. An exogenous cue presented briefly at one of the placeholders was used to direct attention to one of the two locations, with the color word presented at the cued location and the color bar at the uncued location, or vice versa, as in Brown et al.'s (2002) study. Unlike in their study, the SOA between the cue and Stroop display onsets was varied, being $100 \mathrm{msec}$ on some trials and $1,050 \mathrm{msec}$ on others. Pattern masks appeared at offset of the Stroop display to ensure that the effective duration of the display was the same as the physical duration.

With a 100 -msec SOA, visual attention should be oriented toward the cued location when the Stroop display is presented. The Stroop effect should be larger when the color word is at the cued location than when it is at the uncued location, as in Brown et al.'s (2002) study. If meaning of the color word affects performance only when visual attention is directed to it, the Stroop effect should be eliminated when the color word is presented at the uncued location. If the pattern of cuing results at a $100-\mathrm{msec}$ SOA is due to allocation of visual attention to the cued location, the results should be reversed at a 1,050-msec SOA. At the long SOA, visual attention should have shifted to the uncued location prior to onset of the Stroop display, resulting in a smaller Stroop effect when the color word is presented at the cued location than when it is presented at the uncued location.

\section{Participants \\ Twenty-four undergraduate students at Korea University partici- pated to fulfill a course requirement. All had normal or corrected-to- normal visual acuity and color vision as determined by self-report.}

\section{Stimuli and Apparatus}

The stimuli were presented against a dark gray background on a CRT monitor (17 in.) of a personal computer viewed at a distance of approximately $60 \mathrm{~cm}$. The stimuli were controlled by E-Prime software (Version 1.2; Psychology Software Tools, Pittsburgh, PA). Manual responses were made by pressing one of four keys (the two leftmost or the two rightmost keys on an E-Prime response box) with the index and middle fingers of each hand. The colors red, yellow, green, and blue were assigned to the four keys in a left-to-right order for all the participants.

The color carrier was a blue $(\mathrm{R}=0, \mathrm{G}=0, \mathrm{~B}=255)$, green $(\mathrm{R}=0, \mathrm{G}=168, \mathrm{~B}=20)$, red $(\mathrm{R}=255, \mathrm{G}=0, \mathrm{~B}=0)$, or yellow $(\mathrm{R}=255, \mathrm{G}=255, \mathrm{~B}=0)$ color bar $\left(2.24^{\circ} \times 1.05^{\circ}\right)$. The color word was 파랑 [palang] ("blue" in Korean), 초록 [cholok] ("green" in Korean), 빨 강 [palgang] ("red" in Korean), or 노랑 [nolang] ("yellow" in Korean), presented in white. The placeholder was an outline rectangle $\left(2.39^{\circ} \times 1.24^{\circ}\right)$ with a line width of $0.14^{\circ}$ in gray. Displays were created by positioning three placeholders vertically at the center of the screen. The fixation point $\left(0.57^{\circ} \times 0.57^{\circ}\right)$ was located in the middle of the center placeholder. Each peripheral placeholder was separated $3.1^{\circ}$ from the fixation point. An exogenous cue was luminance and thickness changes of the placeholder. One of two peripheral placeholders changed its color from gray to white and became $0.1^{\circ}$ thicker when it was cued for $50 \mathrm{msec}$.

\section{Procedure}

The participants performed the experiment individually under dim light. They were instructed to identify the color of the color bar as quickly and accurately as possible and to ignore the color word. Each participant performed a 40 -trial practice block and a 240 -trial test block. SOA was $100 \mathrm{msec}$ on half of the total trials and $1,050 \mathrm{msec}$ on the other half, varying randomly within the blocks. For each SOA, the color of the color bar and the meaning of the color word were congruent on half of the total trials and incongruent on the other half. The exogenous cue was randomly presented in one of the peripheral placeholders. The validity of cuing was $50 \%$.

The stimulus presentation on a trial is depicted in Figure 1. Each trial began with onset of three placeholders arranged vertically, the

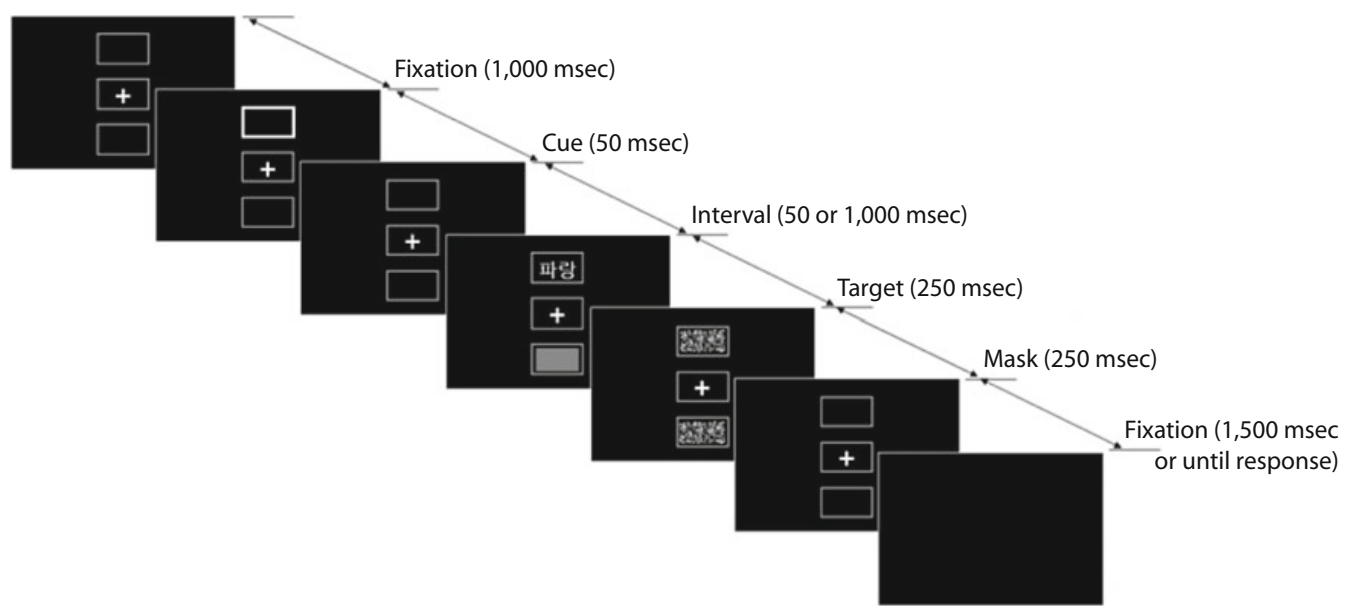

Figure 1. Example of a sequence of events on a trial in Experiment 1. The color of the target color bar, depicted in the figure by gray, could be blue, green, red, or yellow. 
center one of which contained a plus sign on which the participants were told to fixate throughout the trial. After $1,000 \mathrm{msec}$, an exogenous cue flashed for $50 \mathrm{msec}$. A color bar and color word were presented for $250 \mathrm{msec}$ in the peripheral placeholders 50 or $1,000 \mathrm{msec}$ after offset of the exogenous cue (i.e., at SOAs of 100 and 1,050 msec). At stimulus offset, each of the peripheral placeholders was filled with a mask, which was a white noise rectangle $\left(2.24^{\circ} \times 1.05^{\circ}\right.$; see Figure 1). The masks remained visible for $250 \mathrm{msec}$ in order to prevent the color word from being identified from sensory memory. After the masking display, the fixation point and the three placeholders remained on the display until a response was executed. In the case of an incorrect response, auditory feedback was given for $150 \mathrm{msec}$. After responses, a blank display was presented for $1,000 \mathrm{msec}$, followed by onset of the next fixation display. All the experimental conditions were intermixed and randomly presented.

\section{Results}

RTs less than $150 \mathrm{msec}$ or greater than $1,500 \mathrm{msec}$ $(0.69 \%$ of the total trials) were removed as outliers. Mean RT and percent error (PE) were calculated for each participant as a function of SOA (100 or 1,050 msec), color word location (cued or uncued location), and congruency (congruent or incongruent color word; see Tables 1 and 2 for mean RTs and PEs, respectively). ANOVAs were conducted on the RT and PE data, with those variables as within-subjects factors. The $\alpha$ level for all the statistical analyses in this study was .05.

\section{Response Time}

The main effect of SOA was significant $[F(1,23)=$ $\left.6.38, M S_{\mathrm{e}}=1,258\right]$. Mean RT was $13 \mathrm{msec}$ longer at the $100-\mathrm{msec}$ SOA $(M=568 \mathrm{msec})$ than at the $1,050-\mathrm{msec}$

Table 1

Mean Response Times (in Milliseconds; With Standard Deviations) in Experiment 1 As a Function of Stimulus Onset Asynchrony (SOA), Cued Stimulus, and Congruency

\begin{tabular}{|c|c|c|c|c|c|}
\hline \multirow{3}{*}{$\begin{array}{l}\text { SOA and } \\
\text { Color Word } \\
\text { Location }\end{array}$} & \multicolumn{4}{|c|}{ Congruency } & \multirow{3}{*}{$\begin{array}{l}\text { Stroop } \\
\text { Effect }\end{array}$} \\
\hline & \multicolumn{2}{|c|}{ Congruent } & \multicolumn{2}{|c|}{ Incongruent } & \\
\hline & $M$ & $S D$ & $M$ & $S D$ & \\
\hline \multicolumn{6}{|l|}{$100 \mathrm{msec}$} \\
\hline Cued & 561 & 47.80 & 587 & 62.24 & 26 \\
\hline Uncued & 555 & 56.43 & 569 & 60.68 & 14 \\
\hline \multicolumn{6}{|l|}{$1,050 \mathrm{msec}$} \\
\hline Cued & 545 & 59.31 & 559 & 71.05 & 14 \\
\hline Uncued & 542 & 54.81 & 573 & 69.51 & 31 \\
\hline
\end{tabular}

Note-Stroop effect $=$ incongruent minus congruent.

Table 2

Percentages of Errors (With Standard Deviations) in Experiment 1 As a Function of Stimulus Onset Asynchrony (SOA), Cued Stimulus, and Congruency

\begin{tabular}{|c|c|c|c|c|c|}
\hline \multirow{3}{*}{$\begin{array}{l}\text { SOA and } \\
\text { Color Word } \\
\text { Location }\end{array}$} & \multicolumn{4}{|c|}{ Congruency } & \multirow{3}{*}{$\begin{array}{l}\text { Stroop } \\
\text { Effect }\end{array}$} \\
\hline & \multicolumn{2}{|c|}{ Congruent } & \multicolumn{2}{|c|}{ Incongruent } & \\
\hline & $M$ & $S D$ & $M$ & $S D$ & \\
\hline \multicolumn{6}{|l|}{$100 \mathrm{msec}$} \\
\hline Cued & 3.77 & 4.22 & 4.34 & 5.26 & 0.57 \\
\hline Uncued & 3.34 & 3.41 & 4.63 & 3.91 & 1.29 \\
\hline \multicolumn{6}{|l|}{$1,050 \mathrm{msec}$} \\
\hline Cued & 3.53 & 3.99 & 2.79 & 3.06 & -0.74 \\
\hline Uncued & 2.37 & 3.20 & 3.06 & 3.80 & 0.69 \\
\hline
\end{tabular}

Note-Stroop effect $=$ incongruent minus congruent.
SOA $(M=555 \mathrm{msec})$. Color word location showed no main effect $\left[F(1,23)=1.20, M S_{\mathrm{e}}=398, p=.29\right]$, but it interacted with SOA $\left[F(1,23)=11.09, M S_{\mathrm{e}}=322\right]$. At the 100-msec SOA, RT was 12 msec shorter when the color word was presented at the uncued location (and the color bar at the cued location; $M=562 \mathrm{msec}$ ) rather than at the cued location $(M=574 \mathrm{msec})\left[F(1,23)=13.76, M S_{\mathrm{e}}=\right.$ $242]$. By contrast, at the 1,050-msec SOA, RT was a nonsignificant $6 \mathrm{msec}$ longer when the color word was presented at the uncued location (and the color bar at the cued location; $M=558 \mathrm{msec}$ ) rather than at the cued location $(M=552 \mathrm{msec})\left[F(1,23)=1.51, M S_{\mathrm{e}}=478, p=.23\right]$.

The main effect of congruency was significant $\left[F(1,23)=19.16, M S_{\mathrm{e}}=1,129\right]$. Responses showed a 21msec Stroop effect, being faster when the color word was congruent with the color bar $(M=551 \mathrm{msec})$ than when it was incongruent $(M=572 \mathrm{msec})$. Of importance, the three-way interaction of SOA, color word location, and congruency was also significant $\left[F(1,23)=6.95, M S_{\mathrm{e}}=\right.$ 349 ]. At the 100 -msec SOA, the Stroop effect was a nonsignificant $12 \mathrm{msec}$ larger when the color word was presented at the cued location $(26 \mathrm{msec})$ than when it was presented at the uncued location $(14 \mathrm{msec})[F(1,23)=$ $\left.1.77, M S_{\mathrm{e}}=418, p=.20\right]$. In contrast, at the $1,050-\mathrm{msec}$ SOA, the Stroop effect was $17 \mathrm{msec}$ smaller when the color word was presented at the cued location $(14 \mathrm{msec})$ than when it was presented at the uncued location $(31 \mathrm{msec})$ $\left[F(1,23)=7.11, M S_{\mathrm{e}}=253\right]$. For all combinations of SOA and cued versus uncued location, the Stroop effect was statistically significant $\left[F_{\mathrm{S}}(1,23) \geq 5.90\right]$.

\section{Percent Error}

The only term to approach significance was the main effect of SOA $[F(1,23)=3.89, p=.06]$. PE tended to be higher at the $100-\mathrm{msec}$ SOA $(4.02 \%)$ than at the 1,050-msec SOA (2.94\%).

\section{Discussion}

SOA interacted with location of the color bar in a manner consistent with IOR. At the 100-msec SOA, RT was shorter when the color bar was presented at the cued location rather than at the uncued location, but at the 1,050 -msec SOA, this cuing effect was reversed to a nonsignificantly shorter RT when the color bar was presented at the uncued location rather than at the cued location.

In accord with the supposition that focused attention was more likely to be oriented to the cued location with a short SOA but to the uncued location with a long SOA, the Stroop effect also varied as a function of whether the color bar or the color word was presented at the cued location. With a $100-\mathrm{msec}$ SOA, the Stroop effect tended to be smaller when the color bar was at the cued location and the color word at the uncued location than when their locations were switched. In contrast, with a 1,050-msec SOA, the Stroop effect was larger when the color bar was at the cued location and the color word at the uncued location than when their locations were switched. This outcome agrees with that of Brown et al. (2002) in suggesting that color word processing is modulated by attention, but it goes beyond their results in dissociating the locus of at- 
tention from properties of the cue itself: At the long SOA, the larger Stroop effect occurs when the color word is at the uncued location, to which attention is presumably directed, rather than at the cued location.

Although the participants were told to maintain their gaze on the fixation point, it is possible that the eyes did not remain fixated on that point, because the relevant color bar was presented at a location above or below the fixation point. If the participants initially shifted fixation to the cued stimulus location at the $100-\mathrm{msec}$ SOA and then to the uncued stimulus location at the $1,050-\mathrm{msec}$ SOA, processing of the color word when it was at the unattended location may have been impaired because it was not in foveal vision but the color bar was. According to this possibility, at the 1,050-msec SOA, the smaller Stroop effect when the color word occurred at the cued location was due to peripheral sensory factors, and not to direction of visual attention.

\section{EXPERIMENT 2}

The results of Experiment 1 are consistent with the assumption that a smaller Stroop effect occurred if the color word was presented at the unattended location, regardless of whether the SOA was short or long. However, although the Stroop trials provided evidence suggestive of IOR, there were no typical IOR trials on which only the color bar was presented at the cued or uncued location. One purpose of Experiment 2 was to modify the procedure so that single-stimulus IOR trials were randomly intermixed with the Stroop trials. For the IOR trials, the color bar was presented without a color word in the placeholder placed above or below a center placeholder.

For the Stroop trials, the color bar was always presented in the center placeholder, whereas the color word was presented in one of the peripheral placeholders (cued or uncued). By presenting the color bar in the center place- holder on all Stroop trials, the participants would be induced more to focus attention, and maintain fixation, on the color bar than in Experiment 1, reducing the likelihood that any effects were due to eye movements. Also, this method allowed manipulation of whether the color word was at the cued or the uncued peripheral location, while keeping the color bar at a constant location. The visual attention and automatic processing accounts of the Stroop effect make predictions with regard to color word location that are the same as those in Experiment 1.

\section{Method}

Twenty-four new undergraduate students at Korea University participated to fulfill a course requirement. All reported having normal or corrected-to-normal visual acuity and color vision.

The apparatus, stimuli, and procedure were similar to those in Experiment 1 , with the following exceptions. Each participant received a 36-trial practice block, followed by two 180 -trial test blocks. On all trials, the upper or lower placeholder was cued exogenously. On a third of the trials, only the color bar was presented in an upper or lower placeholder (IOR trials). On the rest of the trials, the color bar was presented in the center placeholder, and a color word was presented in the upper or lower placeholder (Stroop trials). The stimulus presentation on a Stroop trial is depicted in Figure 2. IOR and Stroop trials were randomly intermixed.

\section{Results}

Using the same RT cutoff criteria as those in Experiment $1,0.93 \%$ of the trials were removed.

For the IOR trials, mean RT and PE were calculated for each participant as a function of SOA (100 or 1,050 msec) and color bar location (cued or uncued). ANOVAs were conducted on the RT and PE data, with those variables as within-subjects factors. For the Stroop trials, the independent variables were SOA, congruency (congruent or incongruent), and color word location (cued or uncued). Mean RT and PE data are shown in Tables 3 and 4, respectively.

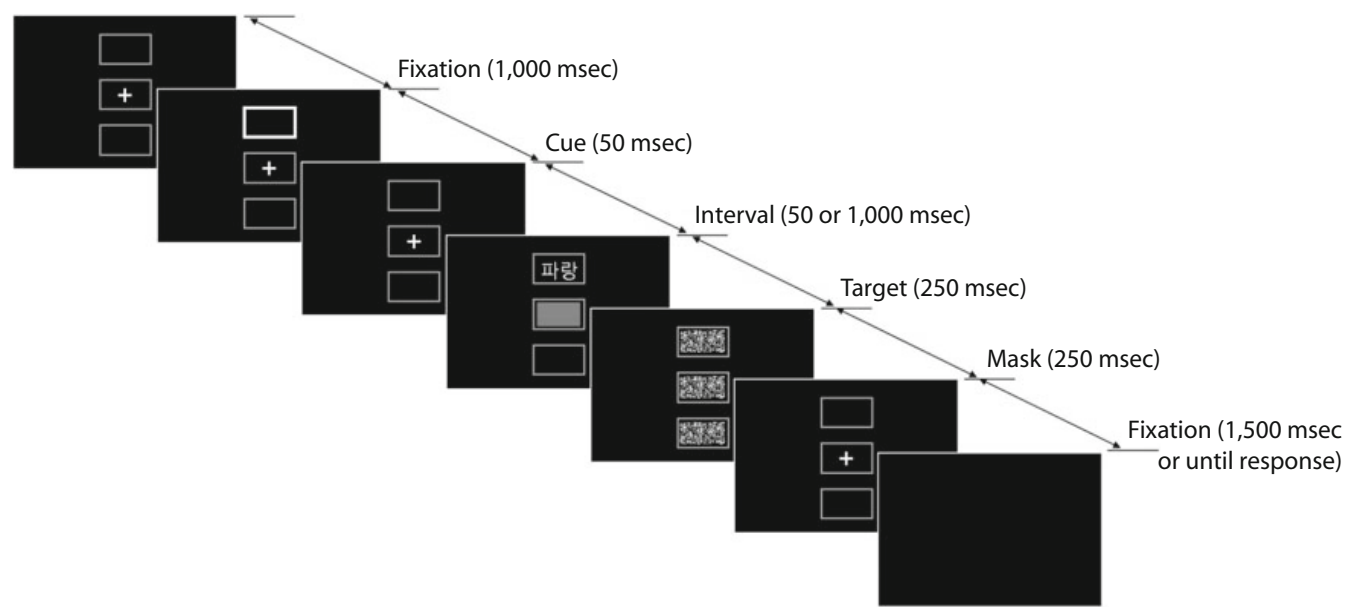

Figure 2. Example of a sequence of events on a trial in Experiment 2. The color of the target color bar, depicted in the figure by gray, could be blue, green, red, or yellow. 
Table 3

Mean Response Times (in Milliseconds, With Standard Deviations) in Experiment 2 As a Function of Cued Stimulus and Stimulus Onset Asynchrony (SOA) on Inhibition of Return (IOR) Trials, and SOA, Congruency, and Color Word Location on Stroop Trials

\begin{tabular}{|c|c|c|c|c|c|}
\hline \multirow[b]{3}{*}{ SOA } & \multicolumn{4}{|c|}{$\begin{array}{l}\text { IOR Trials } \\
\text { Color Bar Location }\end{array}$} & \multirow{3}{*}{$\begin{array}{l}\text { Cuing } \\
\text { Effect }\end{array}$} \\
\hline & \multicolumn{2}{|c|}{ Cued } & \multicolumn{2}{|c|}{ Uncued } & \\
\hline & $M$ & $S D$ & $M$ & $S D$ & \\
\hline $100 \mathrm{msec}$ & 638 & 79.58 & 654 & 88.50 & 16 \\
\hline $1,050 \mathrm{msec}$ & 643 & 94.74 & 629 & 84.81 & -14 \\
\hline \multicolumn{6}{|c|}{ Stroop Trials } \\
\hline \multirow{3}{*}{$\begin{array}{l}\text { SOA and } \\
\text { Color Word } \\
\text { Location }\end{array}$} & \multicolumn{4}{|c|}{ Congruency } & \\
\hline & \multicolumn{2}{|c|}{ Congruent } & \multicolumn{2}{|c|}{ Incongruent } & Stroop \\
\hline & $M$ & $S D$ & $M$ & $S D$ & Effect \\
\hline \multicolumn{6}{|l|}{$100 \mathrm{msec}$} \\
\hline Cued & 606 & 72.44 & 633 & 85.71 & 27 \\
\hline Uncued & 610 & 81.75 & 616 & 83.73 & 6 \\
\hline \multicolumn{6}{|l|}{$1,050 \mathrm{msec}$} \\
\hline Cued & 601 & 85.57 & 610 & 91.20 & 9 \\
\hline Uncued & 592 & 81.85 & 620 & 103.13 & 28 \\
\hline
\end{tabular}

Note - Cuing effect $=$ uncued minus cued; Stroop effect $=$ incongruent minus congruent.

Table 4

Percentages of Errors (With Standard Deviations) in Experiment 2 As a Function of Cued Stimulus and Stimulus Onset Asynchrony (SOA) on Inhibition of Return (IOR) Trials, and SOA, Congruency, and Color Word Location on Stroop Trials

\begin{tabular}{|c|c|c|c|c|c|}
\hline \multirow[b]{3}{*}{ SOA } & \multicolumn{4}{|c|}{$\begin{array}{l}\text { IOR Trials } \\
\text { Color Bar Location }\end{array}$} & \multirow{3}{*}{$\begin{array}{l}\text { Cuing } \\
\text { Effect }\end{array}$} \\
\hline & \multicolumn{2}{|c|}{ Cued } & \multicolumn{2}{|c|}{ Uncued } & \\
\hline & $M$ & $S D$ & $M$ & $S D$ & \\
\hline $100 \mathrm{msec}$ & 2.43 & 2.96 & 2.76 & 3.95 & 0.33 \\
\hline $1,050 \mathrm{msec}$ & 4.22 & 5.24 & 3.60 & 3.87 & -0.62 \\
\hline \multicolumn{6}{|c|}{ Stroop Trials } \\
\hline \multirow{3}{*}{$\begin{array}{l}\text { SOA and } \\
\text { Color Word } \\
\text { Location }\end{array}$} & \multicolumn{4}{|c|}{ Congruency } & \\
\hline & \multicolumn{2}{|c|}{ Congruent } & \multicolumn{2}{|c|}{ Incongruent } & Stroop \\
\hline & $M$ & $S D$ & $M$ & $S D$ & Effect \\
\hline \multicolumn{6}{|l|}{$100 \mathrm{msec}$} \\
\hline Cued & 1.87 & 2.77 & 3.26 & 3.32 & 1.39 \\
\hline Uncued & 2.15 & 2.96 & 3.94 & 4.65 & 1.79 \\
\hline \multicolumn{6}{|l|}{$1,050 \mathrm{msec}$} \\
\hline Cued & 2.36 & 3.04 & 2.20 & 3.34 & -0.16 \\
\hline Uncued & 2.51 & 4.09 & 3.36 & 4.60 & 0.85 \\
\hline
\end{tabular}

Note-Cuing effect $=$ uncued minus cued; Stroop effect $=$ incongruent minus congruent.

\section{IOR Trials}

RT. The main effects of SOA and color bar location were not significant $\left[F_{\mathrm{s}}(1,23)=1.69\right.$ and $.05, M S_{\mathrm{e}} \mathrm{s}=$ 1,455 and $764, p \mathrm{~s}=.21$ and .82 , respectively], but the interaction of SOA and color bar location was significant $\left[F(1,23)=8.55, M S_{\mathrm{e}}=663\right]$. The cuing advantage was $16 \mathrm{msec}$ at the $100-\mathrm{msec} \mathrm{SOA}\left[F(1,23)=5.35, M S_{\mathrm{e}}=\right.$ $622]$ but $-14 \mathrm{msec}$ at the 1,050 -msec SOA $[F(1,23)=$ $\left.2.95, M S_{\mathrm{e}}=805, p=.10\right]$, showing the shift from positive to negative cuing of location indicative of IOR.
PE. The overall PE was $3.25 \%$. The main effect of SOA was at the .05 level $\left[F(1,23)=4.24, M S_{\mathrm{e}}=9.79, p=\right.$ $.051]$. Mean PE was greater at the $1,050-\operatorname{msec} \operatorname{SOA}(M=$ $3.91)$ than at the $100-\mathrm{msec} \operatorname{SOA}(M=2.60)$. No other term approached significance.

\section{Stroop Trials}

RT. The main effect of SOA was at the .05 level $\left[F(1,23)=4.24, M S_{\mathrm{e}}=1,287, p=.051\right]$. Mean RT was longer at the $100-\mathrm{msec} \operatorname{SOA}(M=616 \mathrm{msec})$ than at the $1,050-\mathrm{msec}$ SOA $(M=606 \mathrm{msec})$. However, the main effect of color word location was not significant $(F<1)$, and that variable did not interact with SOA $[F(1,23)=$ $\left.1.02, M S_{\mathrm{e}}=754, p=.32\right]$. The main effect of congruency was significant $\left[F(1,23)=12.32, M S_{\mathrm{e}}=1,203\right]$. Responses were faster when the target color and the meaning of the color word were congruent $(M=602 \mathrm{msec})$ than when they were incongruent $(M=620 \mathrm{msec})$, reflecting an 18-msec Stroop effect.

Most important, the three-way interaction of SOA, color word location, and congruency was significant $[F(1,23)=$ $\left.8.83, M S_{\mathrm{e}}=554\right]$. Separate analyses showed an interaction of congruency and color word location at both the 100 - and $1,050-\mathrm{msec}$ SOAs $\left[F_{\mathrm{s}}(1,23)=5.92\right.$ and 6.86, $M S_{\mathrm{e}} \mathrm{s}=478$ and 305, respectively]. At the 100-msec SOA, the Stroop effect was $27 \mathrm{msec}$ when the color word was presented at the cued location $\left[F(1,23)=18.46, M S_{\mathrm{e}}=\right.$ 478 ] but only a nonsignificant $6 \mathrm{msec}$ when the color word was presented at the uncued location $(F<1)$. The opposite pattern was obtained at the 1,050-msec SOA: The Stroop effect was $28 \mathrm{msec}$ when the color word was presented at the uncued location $\left[F(1,23)=31.30, M S_{\mathrm{e}}=305\right]$, as compared with only a nonsignificant $9 \mathrm{msec}$ when the color word was presented at the cued location $[F(1,23)=$ $\left.3.58, M S_{\mathrm{e}}=305, p=.07\right]$.

PE. The overall PE was $2.71 \%$. Only the main effect of congruency was significant $\left[F(1,23)=6.52, M S_{\mathrm{e}}=\right.$ 6.93 ]. PE was $2.22 \%$ on the congruent trials and $3.19 \%$ on the incongruent trials, reflecting a $0.97 \%$ Stroop effect.

\section{Discussion}

The results of the IOR trials showed an IOR effect: When the color bar occurred alone at the cued or uncued location, the effect of location on RT varied as a function of SOA. At the 100-msec SOA, RT was shorter when the color bar was presented at the cued location than when it was presented at the uncued location, whereas at the 1,050-msec SOA, this relation was numerically reversed. Although the reversal at the long SOA did not quite attain the .05 level, a combined analysis with the RT data for that SOA from Experiment 1 as a function of color bar location showed a significant reversal $\left[F(1,47)=5.35, M S_{\mathrm{e}}=416\right]$ that did not interact with experiment $(F<1)$. Thus, the data from Experiment 2 converge with those from Experiment 1 to indicate that attention was directed to the cued location at the short SOA but to the uncued location at the long SOA.

On Stroop trials, the color bar always occurred in the center placeholder, upon which the participants fixated to begin the trial, and only the location of the color word 
varied. Thus, the Stroop effect was modulated solely by whether the color word was presented at the cued or the uncued location, since the location of the color bar did not vary. The results showed a pattern similar to that of the Stroop effect results in Experiment 1. This point was emphasized by ANOVAs that included experiment as a factor. The PE data showed no significant effect involving experiment, and the RT data showed only a significant main effect: RT was longer in Experiment $2(M=$ $611 \mathrm{msec}$ ), where, across trial types, the relevant color bar could occur in one of three locations, than in Experiment 1 $(M=561 \mathrm{msec})$, where it occurred in one of only two locations. Thus, although the task sets were different in Experiments 1 and 2, the influence of cuing was similar.

The only other difference from the results in Experiment 1 is that the Stroop effect was not significant when the color word was presented at the unattended location in Experiment 2. Specifically, at the 100-msec SOA, no significant Stroop effect $(5 \mathrm{msec})$ was obtained when the color word was presented at the uncued location, whereas a significant 27-msec Stroop effect was obtained when it was presented at the cued location. At the 1,050-msec SOA, the Stroop effect was nonsignificant when the color word was presented at the cued location $(9 \mathrm{msec})$, whereas a significant Stroop effect $(28 \mathrm{msec})$ was obtained when it was presented at the uncued location. Although not significant at the unattended locations, there was a 7-msec overall tendency toward a Stroop effect, suggesting that there still may be a small residual effect. However, analysis of just the trials for the two "unattended" locations (uncued for the short SOA and cued for the long SOA) still showed no significant Stroop effect $\left[F(1,23)=2.58, M S_{\mathrm{e}}=519, p=.12\right]$.

\section{GENERAL DISCUSSION}

If attention modulates the Stroop effect obtained when a color bar and color word are presented, the effect should be larger if attention is directed to the color word than if it is not. A strong implication of the hypothesis that the location to which attention is directed modulates processing of the color word is that the influence of an exogenous cue on the Stroop effect should be reversed at longer SOAs, as compared with shorter ones: The Stroop effect should be larger when the color word occurs at the cued location for short SOAs but smaller for long SOAs, due to IOR (Posner \& Cohen, 1984). The present experiments tested this prediction of the attention hypothesis, measuring the Stroop effect as a function of whether the color word was presented at the cued or the uncued location when the SOA between an exogenous cue and Stroop stimuli was 100 or $1,050 \mathrm{msec}$. In addition, procedures were implemented with the intent of restricting attention to the stimulus at the attended location: Visible placeholders provided precise marking of the locations at which stimuli would appear, and pattern masks displayed at offset of the Stroop stimuli minimized the possibility of shifting attention to process an item from a persisting sensory image.

As is typical of studies that use exogenous cues, when the relevant color bar occurred $100 \mathrm{msec}$ after onset of the cue (luminance change of one of the placeholders), the RT was shorter if the target color bar was at the cued location than if it was at the uncued location. In contrast, when the SOA was $1,050 \mathrm{msec}$, RT tended to be longer if the color bar was at the cued location rather than the uncued location. This result pattern was evident in both experiments, being significant in a combined analysis. For the trials in which both the color bar and a color word were presented, Experiments 1 and 2 consistently showed the Stroop effect to be smaller when the color word was displayed at the unattended location rather than the attended location. In Experiment 1, the Stroop effect was numerically smaller when the color bar was at the cued location and the color word at the uncued location if the SOA was $100 \mathrm{msec}$, but this relation was reversed if the SOA was 1,050 msec. In Experiment 2, in which the color bar was presented at fixation for all the Stroop trials, the Stroop effect was larger when the color word appeared at the cued peripheral location rather than at the uncued location with a $100-\mathrm{msec} \mathrm{SOA}$, with the pattern again reversed with a 1,050-msec SOA. This reduction in Stroop effect when the color word occurred at an unattended location was of similar size in the two experiments (15 and $20 \mathrm{msec}$, respectively).

A small residual Stroop effect was evident when the color word occurred at the unattended location (significant at $14 \mathrm{msec}$ and nonsignificant at $7 \mathrm{msec}$ in Experiments 1 and 2, respectively). This effect could be due to activation produced automatically by the color word or to attention being directed to the "unattended" location to some degree or on some proportion of trials. The latter alternative remains an option because it may be possible to shift attention to irrelevant items with display durations as short as $100 \mathrm{msec}$ (Lachter et al., 2008), as compared with the 250msec duration of displays in the present study. The residual Stroop effects in both experiments were much smaller than the 47-msec effect found by Brown et al. (2002) when, after a 100-msec SOA, the color word occurred in the uncued location and the color bar in the cued location. The larger residual effect in Brown et al.'s (2002) study could be due to their not using placeholders or pattern masks to control attention allocation. A more likely factor, though, is that Brown et al. (2002) used spoken color-naming responses, which have a more direct relation to color words than do keypresses (e.g., Lu \& Proctor, 2001). Consistent with this possibility, presentation of the color word at the cued location after a 100-msec SOA produced a Stroop effect of $68 \mathrm{msec}$ in Brown et al.'s (2002) study, as compared with 26 and $27 \mathrm{msec}$, respectively, in the present Experiments 1 and 2. This difference could reflect stronger activation of vocal naming responses than of keypress responses by either semantic or phonological codes (Kahan, Sellinger, \& Broman-Fulks, 2006). Despite the large difference in size of baseline Stroop effects, the reduction when the color word occurred at the unattended location was of similar magnitude in Brown et al.'s (2002) study and ours. The combined results of their and our experiments suggest that the influence of visual attention may be independent of response mode. They also imply that issues of automaticity of word processing require consideration of the response mode, and not just of stimulus properties. 
That the size of the Stroop effect was smaller not just when the color word occurred at the uncued location, as in Brown et al.'s (2002) study and with the 100-msec SOA in the present study, but also when it occurred at the presumably unattended location (which was the cued location for the 1,050-msec SOA) provides strong evidence that processing of the color word benefits from visual attention. Several other findings suggest that processing of the color word is modulated by the location to which attention is oriented. For example, Cho et al. (2006) found that the size of the Stroop effect decreased when display duration was shortened if the color word was presented as a distractor, but not if the color word was presented as the color carrier. Kim et al. (2008) showed that modulation of the Stroop effect by display duration was not due to a change in readability or perceptual difficulty. If the color word is processed automatically, without modulation by attention, the size of the Stroop effect should not have been affected by display duration, regardless of whether the color word was presented as a color carrier or a distractor.

\section{Inhibitory Tagging Mechanism}

Fuentes, Vivas, and Humphreys (1999) obtained results suggesting that when stimuli are presented at locations subject to IOR, not only is stimulus detection delayed, but also processing is affected by an inhibitory tagging mechanism. In their Experiment 3, a standard flanker effect was found when a distractor was presented at the uncued location: The RT was longer when the flanking distractor signaled a response incompatible with the target than when it signaled a compatible response. However, when the distractor was presented at the cued location, which was subject to IOR, the flanker effect was reversed: Responses were faster when the distractor was incompatible than when it was compatible. According to Fuentes et al., this reversed flanker effect is due to the inhibitory tagging mechanism preventing "stimuli at inhibited locations from contacting associated responses" (p. 162). That is, when a compatible distractor is presented at the location subject to IOR, the response to the target is delayed, because the link to the correct response is disconnected. But when an incompatible distractor is presented at the location subject to IOR, the response is speeded, because the link to the incorrect response is disconnected.

Vivas and Fuentes (2001) provided evidence that this inhibitory tagging mechanism operates in the Stroop task. In their Experiment 1, an integrated Stroop stimulus (colored color word) or a colored string of four Xs was presented at the cued or uncued location $1,250 \mathrm{msec}$ after onset of a peripheral cue. The Stroop effect was smaller for stimuli at the cued location than for those at the uncued location. Experiment 2 used the same SOA between peripheral cue and appearance of a distractor color word or string of four Xs (in white) in the cued or the uncued location. A color bar, to which a response was to be made, was presented just below the distractor location after a delay of 250,350, 600 , or $2,650 \mathrm{msec}$ between onsets. For trials on which the initial stimulus was a color word, the color bar was always incongruent with that signified by the word. With a 250 -msec SOA, the Stroop effect was only $3 \mathrm{msec}$ when the distractor appeared at the cued location, as compared with $38 \mathrm{msec}$ when it appeared at the uncued location. According to Vivas and Fuentes, the inhibitory tagging mechanism prevented the color word from connecting with its associated response when it was presented at the cued location, resulting in reduction of the Stroop effect in Experiment 1 and its elimination in Experiment 2.

For the present study, one could argue that the inhibitory tagging mechanism caused the reduced Stroop effect obtained when the color word was presented at the location subject to IOR. However, details of the results do not seem consistent with such an account. Since the inhibitory tagging mechanism is supposed to inhibit activation of the response associated with the stimulus at the location subject to IOR, the effect of such tagging should be particularly deleterious for congruent trials, because the tagging should inhibit not only the beneficial activation of the correct response produced by the color word on those trials, but also, possibly, the activation produced by the relevant color bar. Yet RT for congruent trials varied only slightly as a function of whether the color word was at the cued or the uncued location. Moreover, because the inhibitory tagging mechanism should not be operative at the short 100-msec SOA, which is not subject to IOR, the tagging account cannot easily explain why the exogenous cue had an influence on the Stroop effect at the short SOA opposite that at the 1,050-msec SOA. Resolution of the roles of direction of visual attention and inhibitory tagging will require experiments that include both integrated and separated Stroop stimulus displays presented with short and long SOAs between cue and stimulus onsets.

\section{CONCLUSION}

By varying the interval by which an exogenous cue preceded onset of the Stroop stimulus, we showed that the meaning of the color word impacted performance in the Stroop task more when focused visual attention was deployed to the word than when it was not. Thus, processing of word meaning for Stroop stimuli is not strongly automatic. Although several lines of evidence agree in suggesting that visual attention is needed to process the color word at least up to the semantic level of processing (e.g., McCann, Folk, \& Johnston, 1992), there is another line of evidence that an automatic component of word recognition may contribute to a small part of the Stroop effect. Lachter et al. (2008) found a significant Stroop effect even though they restricted visual attention to a color bar at fixation, using various procedures, and concluded that processing of the color word can occur without the focus of visual attention. The extent to which processing of the color word can occur without visual attention remains an open issue, but our results obtained with an IOR procedure indicate that the location to which attention is directed plays a substantial role in modulating the influence of the color word on performance.

\section{AUTHOR NOTE}

This research was supported by a Korean Research Foundation Grant funded by the Korean Government (KRF-2008-321-H00008) and a Korea Science and Engineering Foundation (KOSEF) Grant funded by the Korean Government (MOST-2006-05110). R.W.P.'s work on this project was supported in part by Grant W911NF-05-1-0153 from the Army Research Office. Correspondence should be sent to Y. S. Cho, De- 
partment of Psychology, Korea University, Anam-dong Seongbuk-Gu, Seoul 136-701, Korea (e-mail: yscho_psych@korea.ac.kr).

\section{REFERENCES}

Besner, D., \& Stolz, J.A. (1999). What kind of attention modulates the Stroop effect? Psychonomic Bulletin \& Review, 6, 99-104.

Besner, D., Stolz, J. A., \& Boutilier, C. (1997). The Stroop effect and the myth of automaticity. Psychonomic Bulletin \& Review, 4, 221-225.

Brown, T. L., Gore, C. L., \& CARr, T. H. (2002). Visual attention and word recognition in Stroop color naming: Is word recognition "automatic"? Journal of Experimental Psychology: General, 131, 220-240. doi:10.1037/0096-3445.131.2.220

Brown, T. L., Roos-Gilbert, L., \& Carr, T. H. (1995). Automaticity and word perception: Evidence from Stroop and Stroop dilution effects. Journal of Experimental Psychology: Learning, Memory, \& Cognition, 21, 1395-1411. doi:10.1037/0278-7393.21.6.1395

Cho, Y. S., Lien, M.-C., \& Proctor, R. W. (2006). Stroop dilution depends on the nature of the color carrier but not on its location. Journal of Experimental Psychology: Human Perception \& Performance, 32, 826-839. doi:10.1037/0096-1523.32.4.826

Cohen, J. D., Dunbar, K., \& McClelland, J. L. (1990). On the control of automatic processes: A parallel distributed processing account of the Stroop effect. Psychological Review, 97, 332-361. doi:10.1037/ 0033-295X.97.3.332

ERIKSEN, B. A., \& ERIKSEN, C. W. (1974). Effects of noise letters upon the identification of a target letter in a nonsearch task. Perception \& Psychophysics, 16, 143-149.

Fuentes, L. J., Vivas, A. B., \& Humphreys, G. W. (1999). Inhibitory tagging of stimulus properties in inhibition of return: Effects on semantic priming and flanker interference. Quarterly Journal of Experimental Psychology, 52A, 149-164. doi:10.1080/027249899391269

Glaser, M. O., \& Glaser, W. R. (1982). Time course analysis of the Stroop phenomenon. Journal of Experimental Psychology. Human Perception \& Performance, 8, 875-894. doi:10.1037/0096 $-1523.8 .6 .875$

Hunt, A. R., \& Kingstone, A. (2003). Inhibition of return: Dissociating attentional and oculomotor components. Journal of Experimental Psychology: Human Perception \& Performance, 29, 1068-1074. doi:10.1016/j.cogbrainres.2003.08.006

Kahan, T. A., Sellinger, J. J., \& Broman-Fulks, J. J. (2006). Associative and phonological priming effects after letter search on the prime. American Journal of Psychology, 119, 239-254.

KAHNEMAN, D., \& CHAJCZYK, D. (1983). Tests of the automaticity of reading: Dilution of Stroop effects by color-irrelevant stimuli. Journal of Experimental Psychology: Human Perception \& Performance, 9, 497-509. doi:10.1037/0096-1523.9.4.497

Kim, H., Cho, Y. S., Yamaguchi, M., \& Proctor, R. W. (2008). Influence of color word availability on the Stroop color-naming effect. Perception \& Psychophysics, 70, 1540-1551. doi:10.3758/PP.70.8.1540

KLEIN, R. M., \& TAYLOR, T. L. (1994). Categories of cognitive inhibition with reference to attention. In D. Dagenbach \& T. H. Carr (Eds.), Inhibitory processes in attention, memory, and language (pp. 113-150). San Diego: Academic Press

Lachter, J., Ruthruff, E., Lien, M.-C., \& McCann, R. S. (2008). Is attention needed for word identification? Evidence from the Stroop paradigm. Psychonomic Bulletin \& Review, 15, 950-955. doi:10.3758/ PBR.15.5.950

LiNDSAY, D. S., \& JACOBY, L. L. (1994). Stroop process dissociations: The relationship between facilitation and interference. Journal of Experimental Psychology: Human Perception \& Performance, 20, 219 234. doi:10.1037/0096-1523.20.2.219

Lu, C.-H., \& Proctor, R. W. (2001). Influence of irrelevant information on human performance: Effects of S-R association strength and relative timing. Quarterly Journal of Experimental Psychology, 54A, 95-136. doi:10.1080/02724980042000048

LupiáñeZ, J., Klein, R. M., \& BARTOLOMEO, P. (2006). Inhibition of return: Twenty years after. Cognitive Neuropsychology, 23, 1003-1014. doi: $10.1080 / 02643290600588095$

Lupiáñez, J., Milán, E. G., Tornay, F. J., Madrid, E., \& Tudela, P. (1997). Does IOR occur in discrimination tasks? Yes, it does, but later. Perception \& Psychophysics, 59, 1241-1254.

MacLEOD, C. M. (1991). Half a century of research on the Stroop ef- fect: An integrative review. Psychological Bulletin, 109, 163-203. doi:10.1037/0033-2909.109.2.163

MacLeod, C. M., \& Dunbar, K. (1988). Training and Stroop-like interference: Evidence for a continuum of automaticity. Journal of Experimental Psychology: Learning, Memory, \& Cognition, 14, 126-135. doi:10.1037/0278-7393.14.1.126

McCann, R. S., Folk, C. L., \& Johnston, J. C. (1992). The role of spatial attention in visual word processing. Journal of Experimental Psychology: Human Perception \& Performance, 18, 1015-1029. doi:10.1037/0096-1523.18.4.1015

Moors, A., \& De Houwer, J. (2006). Automaticity: A theoretical and conceptual analysis. Psychological Bulletin, 132, 297-326. doi:10.1037/0033-2909.132.2.297

NeELY, J. H., \& KAHAN, T. (2001). Is semantic activation automatic? A critical reevaluation. In H. L. Roediger III, J. S. Nairne, I. Neath, \& A. M. Surprenant (Eds.), The nature of remembering: Essays in honor of Robert G. Crowder (pp. 69-93). Washington, DC: American Psychological Association.

Posner, M. I., \& Cohen, Y. (1984). Components of visual orienting. In H. Bouma \& D. G. Bouwhuis (Eds.), Attention and performance X: Control of language processes (pp. 531-556). Hillsdale, NJ: Erlbaum.

Posner, M. I., Rafal, R. D., Choate, L. S., \& Vaughan, J. (1985). Inhibition of return: Neural basis and function. Cognitive Neuropsychology, 2, 221-228. doi:10.1080/02643298508252866

Posner, M. I., \& SNYDER, C. R. R. (1975). Attention and cognitive control. In R. L. Solso (Ed.), Information processing and cognition: The Loyola Symposium (pp. 55-85). Hillsdale, NJ: Erlbaum.

PRIME, D. J., \& WARD, L. M. (2004). Inhibition of return from stimulus to response. Psychological Science, 15, 272-276. doi:10.1111/j.0956 -7976.2004.00665.x

RAFAL, R., \& HENIK, A. (1994). The neurology of inhibition: Integrating controlled and automatic processes. In D. Dagenbach \& T. H. Carr (Eds.), Inhibitory processes in attention, memory, and language (pp. 1-51). San Diego: Academic Press.

Reuter-Lorenz, P. A., JHA, A. P., \& Rosenquist, J. N. (1996). What is inhibited in inhibition of return? Journal of Experimental Psychology: Human Perception \& Performance, 22, 367-378. doi:10.1037/0096 $-1523.22 .2 .367$

Roberts, M. A., \& BeSner, D. (2005). Stroop dilution revisited: Evidence for domain-specific, limited-capacity processing. Journal of Experimental Psychology: Human Perception \& Performance, 31, 3-13. doi:10.1037/0096-1523.31.1.3

Saling, L. L., \& Phillips, J. G. (2007). Automatic behaviour: Efficient not mindless. Brain Research Bulletin, 73, 1-20. doi:10.1016/j .brainresbull.2007.02.009

SCHNEIDER, W., \& ShIFFrin, R. M. (1977). Controlled and automatic human information processing: I. Detection, search, and attention. Psychological Review, 84, 1-66. doi:10.1037/0033-295X.84.1.1

Simon, J. R. (1969). Reactions toward the source of stimulation. Journal of Experimental Psychology, 81, 174-176. doi:10.1037/h0027448

STROOP, J. R. (1935). Studies of interference in serial verbal reactions. Journal of Experimental Psychology, 18, 643-662.

TAYLOR, T. L., \& KLEIN, R. M. (2000). Visual and motor effects in inhibition of return. Journal of Experimental Psychology: Human Perception \& Performance, 26, 1639-1656. doi:10.1037/0096-1523 .26.5.1639

Vivas, A. B., \& Fuentes, L. J. (2001). Stroop interference is affected in inhibition of return. Psychonomic Bulletin \& Review, 8, 315-323.

YeE, P. L., \& Hunt, E. (1991). Individual differences in Stroop dilution: Tests of the attention-capture hypothesis. Journal of Experimental Psychology: Human Perception \& Performance, 17, 715-725. doi:10.1037/0096-1523.17.3.715

\section{NOTE}

1. In Vivas and Fuentes's (2001) Experiment 2, the color word was presented separately from a color bar containing the physical color. Because the purpose was to present the color word prior to the color bar by various intervals, both stimuli always appeared to the same cued or uncued side of fixation.

(Manuscript received August 4, 2008; revision accepted for publication April 1, 2009.) 